\title{
O CONCEITO DE CIDADES INTELIGENTES E SUA APLICABILIDADE EM UMA INSTITUIÇÃO PÚBLICA DE ENSINO SUPERIOR
}

\author{
Carlos Felipe de Oliveira Silva (Fatec Guarulhos) \\ Bárbara Aparecida.Izidorio Brandino (Fatec Guarulhos) \\ Elizangela Geraldina Fraga (Fatec Guarulhos) \\ José Martino Neto (Fatec Guarulhos. Orientador)
}

\section{elizangela.fraga@fatec.sp.gov.br}

\section{RESUMO}

Este artigo tem como objetivo discutir o conceito de cidades inteligentes e sua aplicabilidade em uma instituição pública de Ensino Superior localizada na cidade de Guarulhos/SP. O conceito de cidade inteligente surgiu no final dos anos $90 \mathrm{em}$ um movimento que defendia novas políticas de planejamento urbano. $\mathrm{Na}$ virada do século XXI, a expressão passou a ser usada por empresas de tecnologia para definir a aplicação de sistemas de informação integrados à infraestrutura e serviços urbanos. Diante deste panorama este artigo se justifica pela relação que pretendemos traçar do mundo real com o mundo virtual, onde entidades físicas passam a ter uma única identidade digital. A metodologia utilizada, de caráter qualitativa e exploratória, foi baseada em estudo de caso com coleta de dados em fontes primárias e secundárias realizada nos meses de junho a agosto de 2019 e o uso do software KonberLabDemo. Os resultados mostraram que, a aplicabilidade do conceito de cidades inteligentes em ambientes acadêmicas - smart campus - é um produto/serviço altamente viável, pois proporciona uma maior eficiência nas atividades da gestão da Instituição com consideráveis resultados em favor dos envolvidos - professores, alunos, funcionários. Sendo assim, pretende-se com este trabalho contribuir com pesquisas sobre a gestão de um espaço acadêmico com a concepção de uma cidade inteligente - smart campus - como uma prática viabilizadora do desenvolvimento de um ecossistema urbano inovador, caracterizado por uma 
utilização generalizada de tecnologia da informação e comunicação na gestão de seus recursos.

Palavras-chave: Cidades inteligentes; Smart campus; Educação Superior Tecnológica

\section{INTRODUÇÃO}

Devido a celeridade de mudanças, sobretudo tecnológica com o uso da inteligência artificial e da internet das coisas as Universidades têm atuado como laboratório de experiências - living lab - com pesquisas nas áreas de energias sustentáveis, mobilidade urbana, energia renováveis, visão computacional. Tais pressupostos são baseados nos conceitos das cidades inteligentes os quais focam na aplicação das tecnologias da comunicação e informação para resolver problemas urbanos cujo objetivo é o bem-estar e desenvolvimento do cidadão para a construção de uma sociedade inclusiva, sustentável e que melhore a qualidade de vida em geral. As soluções para seus problemas cotidianos são definidas a partir da real necessidade da população e não em projetos isolados percebidos apenas por financiadores e/ou apoiadores, por exemplo.

Se considerarmos a proposta para um smart campus, a ideia básica de internet das coisas (IoT) se fundamenta, pois eles permitem a interação e conectividade entre si, com outros dispositivos e serviços para alcançar um objetivo. No caso específico deste trabalho, temos como objetivo discutir o conceito de cidade inteligente e sua aplicabilidade em uma instituição pública de ensino superior localizada na cidade de Guarulhos/SP.

A ideia inovadora que teve como precursor o projeto Masdar City, localizado em Abu Dhabi, nos Emirados Árabes Unidos, em 2006 resultante de uma parceria entre o Masdar Institute, o Massachussetts Institute of Technology (MIT) e a empresa Siemens. Em nosso País, a instituição precursora foi a Faculdade de Engenharia de Sorocaba (Facens) em 2015.

Apoiado nos Objetivos de Desenvolvimento Sustentável (ODS) das Nações Unidades, o conceito de smart campus esta descrito desde 2015 na plataforma Agenda 


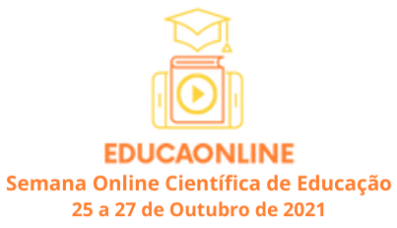

2030 que contem uma lista com 17 objetivos de desenvolvimento sustentável. Para fins desta pesquisa, utilizaremos o ODS 4 (educação de qualidade) que, para as Universidades serve como um selo das Nações Unidas no contexto de uma instituição de ensino superior preocupada com a qualidade de vida dos cidadãos que frequentam o campus e utilizam seus serviços.

Neste sentido, as Universidades, também, podem ser laboratórios para testar tecnologias inovadoras que, depois poderão ser levadas para as cidades. Seria uma das propostas máxima da frase: "agir local, pensar global". No entanto, este trabalho desconsidera aspectos relacionados à educação em aprendizado, que são inerentes ao ambiente analisado.

Sendo assim, este artigo apresenta a iniciativa conceitual de um Smart Campus Ftc Gru - Fatec Guarulhos) que é um estudo em andamento que tem como objetivo principal desenvolver, testar e implantar projetos simples ou de tecnologias avançadas com a participação de toda comunidade acadêmica que convirjam para a melhoria de sua qualidade de vida, enquanto atores do Campus na palma de sua mão. Além disso, apresenta a plataforma móvel Fatec Pocket ${ }^{\circledR}$ criada pelo aluno Bruno Eleodoro do Curso Superior em Tecnologia de Segurança da Informação (Fatec Americana) em 2019.

Em seguida será apresentado o conceito de cidades inteligentes e campus inteligentes (smart campus) e algumas tecnologias relacionadas; descrito a metodologia utilizada pelo grupo para o desenvolvimento do tema e seus desdobramentos e, por fim será descrito o projeto Smart Campus Ftc Gru e sua aplicação móvel no Fatec Pocket®, as considerações finais e as contribuições para trabalhos futuros bem como as referências consultadas.

De acordo com Soares Neto (2018, p.12)

As cidades inteligentes têm foco em um modelo particularizado, com visão moderna do desenvolvimento urbano e que reconhecem a crescente importância das tecnologias da informação e comunicação no direcionamento da competitividade econômica, sustentabilidade ambiental e qualidade de vida geral [...] esse conceito vai além dos aspectos puramente técnicos que caracterizam as cidades como cidades digitais.

Neste aspecto, as informações inteligentes para os cidadãos segundo Chiusoli (2019, p. 10) 


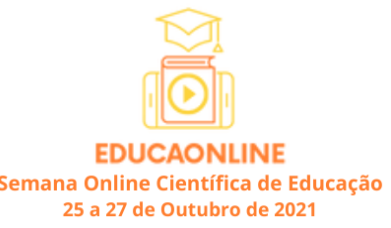

Usam tecnologias de smart computing para tornar os componentes das infraestruturas e serviços críticos - os quais incluem a administração da cidade, educação, assistência à saúde, segurança pública, edifícios, transportes e utilities - mais inteligentes, interconectados e eficientes. Que bem realizam a visão de futuro em várias vertentes - economia, pessoas, governança, mobilidade, meio ambiente e qualidade de vida -, e são construídas sobre a combinação inteligente de atitudes decisivas, independentes e conscientes dos atores que nelas atuam.

Atualmente a expressão Cidades Inteligentes (Smart Cities) está bem estabelecido; porém existem algumas outras expressões que também indicam características similares à ideia de Cidades Inteligente como: Cidades Digitais (Digital City), Cidades do Conhecimento (Knowledge City) e Cidades Conectadas (Wired City). Para efeito deste artigo, utilizaremos a expressão Cidades Inteligentes (Smart Cities).

As principais tecnologias (Figura 1) usadas na criação da infraestrutura de uma cidade inteligente de acordo com Soares Neto (2018, p. 23) seriam:

- Internet das Coisas: para possibilitar a conexão de diversos dispositivos na rede da cidade como sensores, sinais de trânsito e dispositivos de usuários;

- Big Data: para viabilizando o armazenamento e o processamento de grandes quantidades de dados coletados na cidade e

- Computação em Nuvem: para fornecer um ambiente escalável e elástico que suporte a grande demanda de recursos computacionais necessários em uma cidade inteligente.

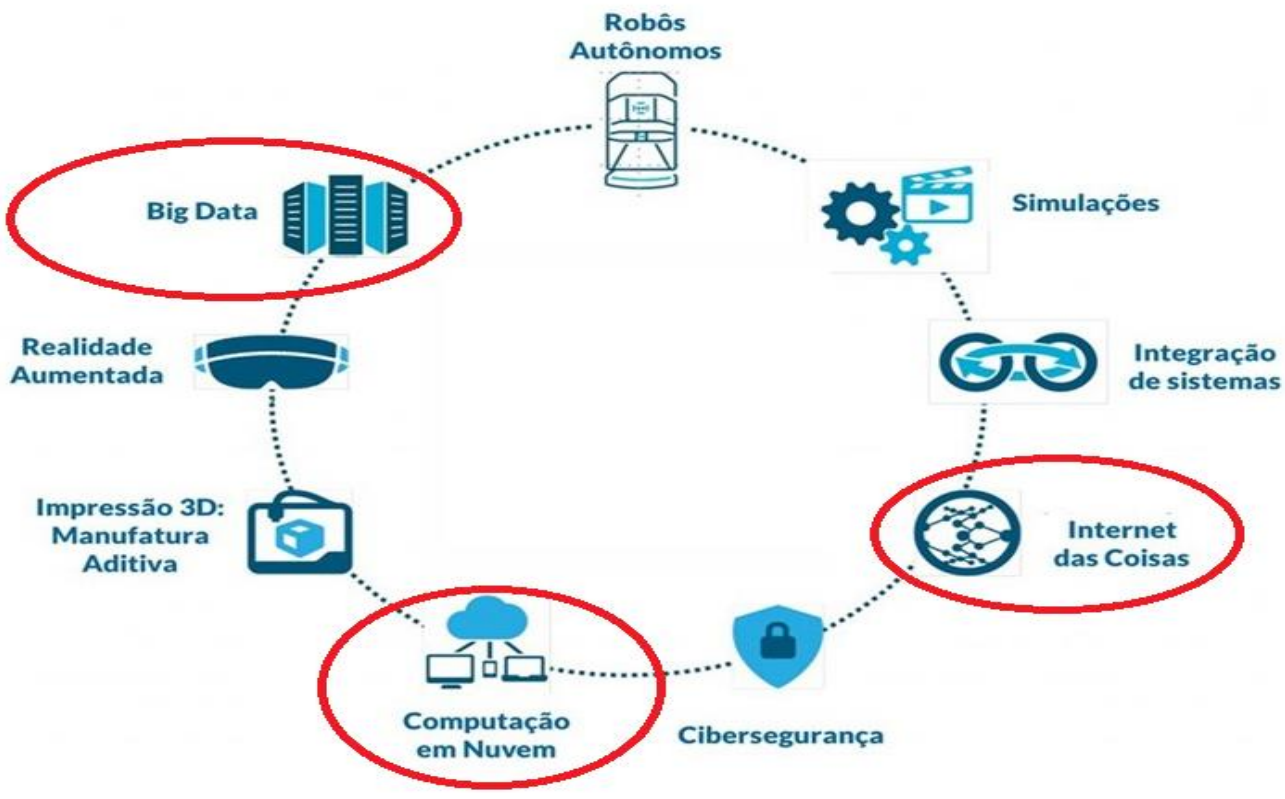

Figura 1: Principais Tecnologias usadas na criação de cidades inteligente

Fonte: adaptada pelos autores de Breda et al (2016, p. 27). 
Existem um amplo entendimento que as cidades inteligentes são caracterizadas pelo uso das tecnologias da informação e comunicação, no entanto, cremos que sua ideia principal seja o aspecto tecnológico da cidade, entre outras coisas, pelo viés da qualidade de vida das pessoas bem como envolver diversas características e habilidades que uma cidade deva possuir para melhorar seu desempenho em determinadas áreas no que tange, principalmente, ao gerenciamento de seus serviços e recursos.

Gallo (2016, p. 18) descreve

Campus inteligente como sendo uma plataforma de aquisição e entrega de dados para impulsionar a análise e melhoria do ambiente de ensino e aprendizagem com ações reais que visem a qualidade de vida dos atores que utilizam aquele espaço com o uso de sensores integrados.

O sensoriamento integrado pode ocorrer em diversos domínios/áreas como:

- $\quad$ Meio ambiente (desenvolvimento sustentável)

- Mobilidade/ tráfego/infraestrutura (acessibilidade)

- $\quad$ Educação/Ensino (uso das TIC’s e dos ambientes virtuais de ensino)

- $\quad$ Segurança (sensoriamento dos ambientes)

- $\quad$ Saúde (aplicações integradas em dispositivos inteligentes)

Os usuários da cidade/campus inteligentes podem auxiliar a gerenciar problemas tais como lixo jogado em local impróprio, buracos nas ruas, má conservação das calçadas, trânsito, pontos de alagamento, iluminação pública defeituosa, focos de dengue, semáforos com defeito etc. A nível de campus, a gestão colaborativa da infraestrutura envolve o uso consciente de energia elétrica, água, relato de problemas percebidos pela comunidade em prédios e no campus de modo geral. Muitas vezes os gestores não ficam cientes de problemas enfrentados pelas pessoas no seu dia-a-dia, dificultando a identificação e a resolução de tais problemas, bem como o planejamento apropriado de investimentos para prevenção e solução desses problemas.

Uma das propostas seria realizada com o uso da plataforma Konker@ que, dentre seus vários desafios técnicos e de negócios apresenta, por exemplo, a proposta da 
construção de um backend (de suporte) de conectividade com o poder da colaboração de todos. (Figura 2).

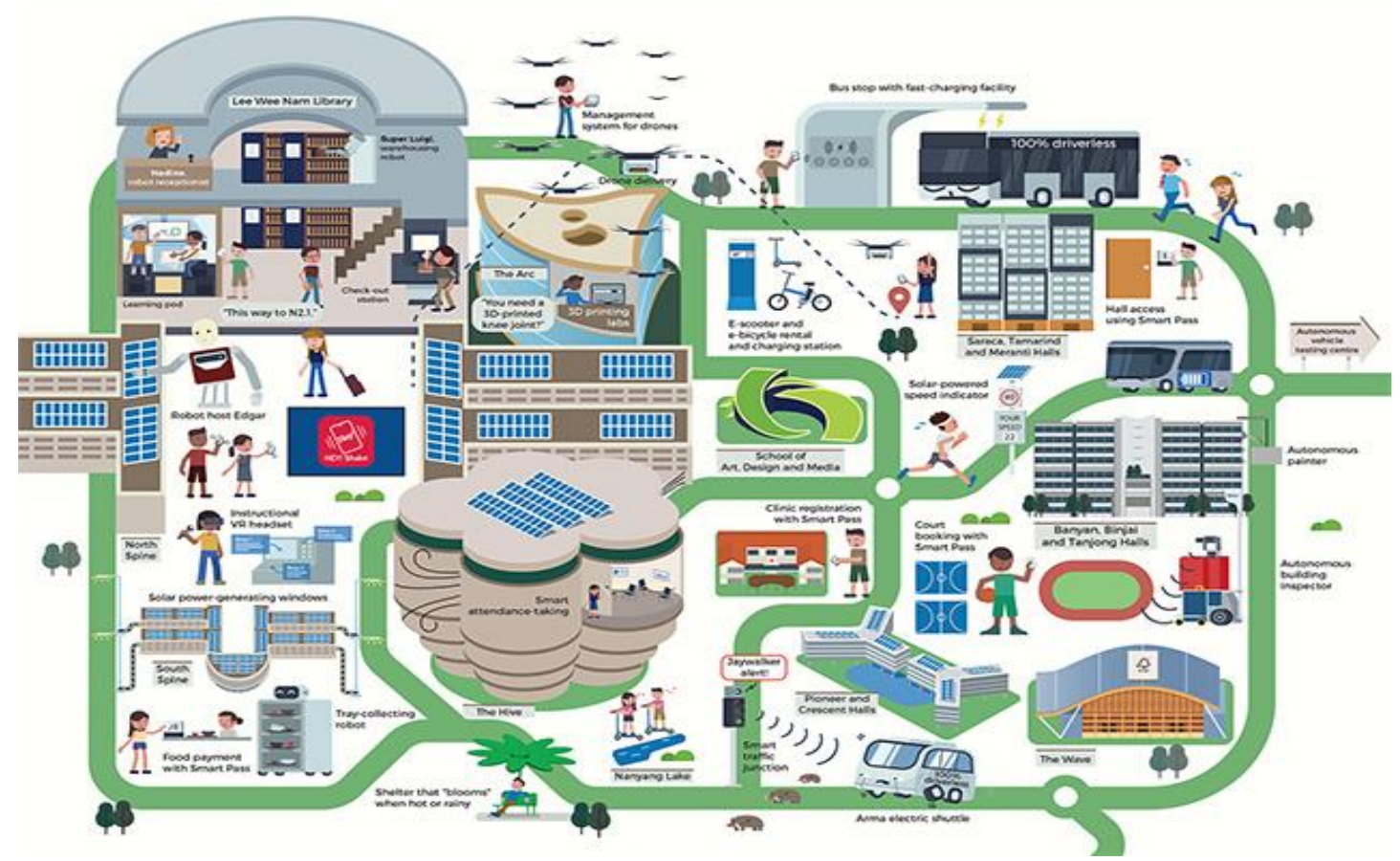

Figura 2: Como criar seu projeto de Smart Campus

Fonte: KonberLabDemo (2019)

\section{METODOLOGIA}

Para este trabalho foi realizada uma pesquisa qualitativa e exploratória baseada em um estudo de caso ao permitir "uma investigação empírica que investiga um fenômeno contemporâneo dentro de seu contexto da vida real (YIN, 2005, p. 32). Um dos critérios que nortearam a escolha do tema como foi a visita de uma das autoras deste artigo ao bairro Cidade Universitária Pedra Branca, construído e desenvolvido com base no conceito de urbanismo sustentável, localizado a $15 \mathrm{~km}$ de Florianópolis, capital de Santa Catarina, no município de Palhoça (Figura 3). 


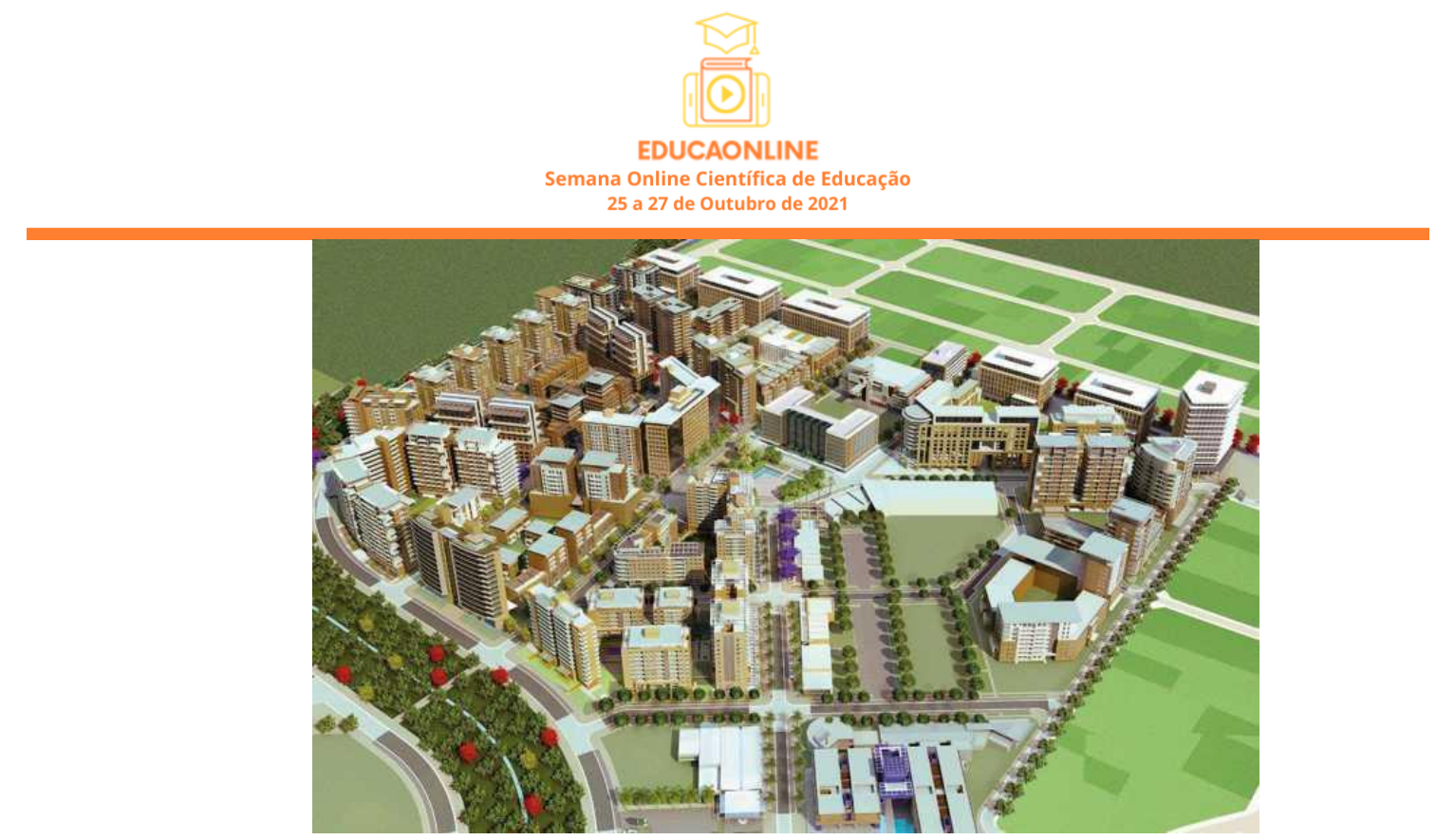

Figura 3: Cidade Universitária Pedra Branca.

Fonte: Cidade Pedra Branca (2019)

A história do bairro teve inicio no final da década de 90, quando se planejou a transformação de uma fazenda familiar, com suas belezas naturais, em um bairro diferenciado que, teve sua expansão consolidada com a presença de uma universidade privada em suas instalações que, trouxe vida e movimento ao empreendimento.

Este empreendimento é todo gerenciado por um complexo sistema que utiliza a IoT em um shopping acadêmico que integra os setores administrativos, coordenação dos cursos, praça de alimentação, livraria, agência bancária, sala de utilidades em uma área total de $30.561,24 \mathrm{~m}^{2}$. Neste espaço, $22.113,58 \mathrm{~m}^{2}$ são ocupados por instalações para a prática esportiva, área verde e ruas.

Optou-se por realizar a pesquisa na Fatec Guarulhos tendo em vista a disponibilidade dos pesquisadores que estudam e trabalham na Unidade. As fontes primárias consistiram em entrevistas presenciais. Entre os entrevistados para o desenvolvimento do presente Trabalho, foram escolhidos, intencionalmente, alunos (60), funcionários (5), Professores (10), Coordenadores (4) e Direção (3) - estes dois últimos grupos por ocuparem atividades chaves dentro da Fatec Guarulhos relacionados diretamente à gestão administrativa e definição das políticas da Faculdade.

Para a coleta de dados, foi elaborado um questionário composto por sete (7) questões fechadas e uma (1) aberta. Optou-se por este instrumento de coleta de dados por ser um “instrumento de coleta de dados constituído por uma série ordenada de perguntas, 


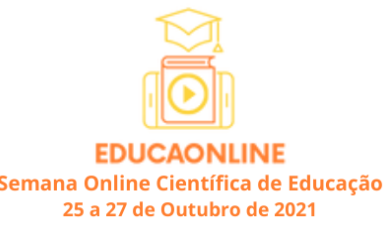

que devem ser respondidas por escrito e sem a presença do entrevistador". (LAKATOS, 2009, p. 86)

As questões abertas foram elaboradas na tentativa de medir a integração organizacional dos envolvidos, através do compartilhamento de valores e do conhecimento da importância de uma comunicação integrada (e na palma da mão ou ao alcance de todos) na Instituição e, as fechadas tiveram o objetivo de identificar com os atores, o (s) principal (is) problema (s) que "impedem" essa identidade digital - meio necessário para haver a troca de informação e interação entre o mundo real e o mundo virtual.

O Instrumento para Coleta de Dados - Questionário - foi distribuído e aplicado nas dependências da Faculdade de Tecnologia de Guarulhos, no mês de agosto de 2019 momento que os pesquisadores tiveram, também, a oportunidade de conhecer todos os ambientes da Instituição além daqueles habituais como: Direção, Diretoria de Serviços Acadêmicos, Diretoria de Serviços Administrativos, Sala dos Professores, Sala da Coordenação, Cozinha dos Funcionários, Refeitório, Sala de depósito dos materiais de higiene e limpeza (no andar térreo), estacionamento, Biblioteca, salas de aula e laboratórios. Os resultados foram processados após cada entrevista de forma conjunta com a pesquisa bibliográfica e, posteriormente com a análise documental. Como fontes secundárias, foram utilizados documentos disponibilizados no portal da internet do Centro Paula Souza.

Por tratar-se de um estudo de caso conceitual, é relevante explicar que os dados se basearam nas interações com os representantes internos da Fatec Guarulhos e na consulta a documentos oficiais não permitindo o confronto de visões, opiniões e julgamento dos autores do artigo.

\section{RESULTADOS E DISCUSSÕES}

A Faculdade de Tecnologia de Guarulhos (FATEC Guarulhos) é uma das Faculdades de Tecnologia do Centro Paula Souza - autarquia do Governo do Estado de São Paulo vinculada à Secretaria de Desenvolvimento Econômico. O Centro Paula Souza administra Faculdades de Tecnologia (Fatecs) e Escolas Técnicas (Etecs) estaduais, além 
das classes descentralizadas - unidades que funcionam com um ou mais cursos técnicos sob a supervisão de uma Etec - em cerca de 300 municípios paulistas. (Centro Paula Souza, 2019).

A Faculdade fora criada pelo Decreto $n^{\circ} 52.059$ de 15 de agosto de 2007 (D.O.E; Poder Executivo, Seção I, São Paulo, 117 (154) -1) e, iniciou suas atividades, em prédio cedido pela Prefeitura Municipal de Guarulhos, em 10 de setembro de 2007 situado à rua João Gonçalves, no 511 (Figura 4). Nesta sede, eram oferecidos os Cursos de Logística Aeroportuária (manhã), Logística (Tarde e Noite) e Gestão Empresarial (EaD) em um prédio de seis (6) andares, incluindo garagem, assim organizado: (Subsolo: garagem, sala de manutenção e depósito de materiais de higiene e limpeza; Térreo: recepção, cozinha dos funcionários, cantina, sala da atlética/diretório acadêmico; $1^{\circ}$ Andar: pavimento em que estão localizados os setores administrativos da Fatec Guarulhos como: Direção Geral, Diretoria de Serviços Administrativos, Diretoria de Serviços Acadêmicos, Secretária, Sala da Coordenação, Sala dos Professores, Sala de Estágio, Sala de Tecnologia da Informação; $2^{\circ}$ Andar: Sala de educação à distância, depósito I, lan-house, biblioteca, sala

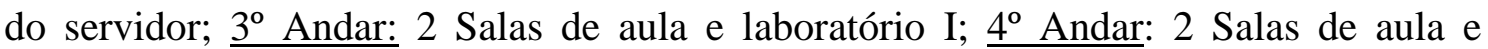

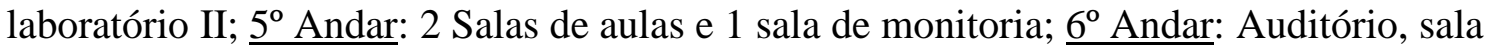
de reuniões, depósito II e 1 sala de aula. Contava em seu quadro de funcionários com 12 funcionários do quadro, 3 estagiários e 15 funcionários terceirizados sendo: 8 vigilantes, 2 funcionários cedidos pela Prefeitura de Guarulhos, 2 funcionários cedidos pela Progresso e Desenvolvimento de Guarulhos (Proguaru) e 3 zeladoras de Empresa Terceirizada.

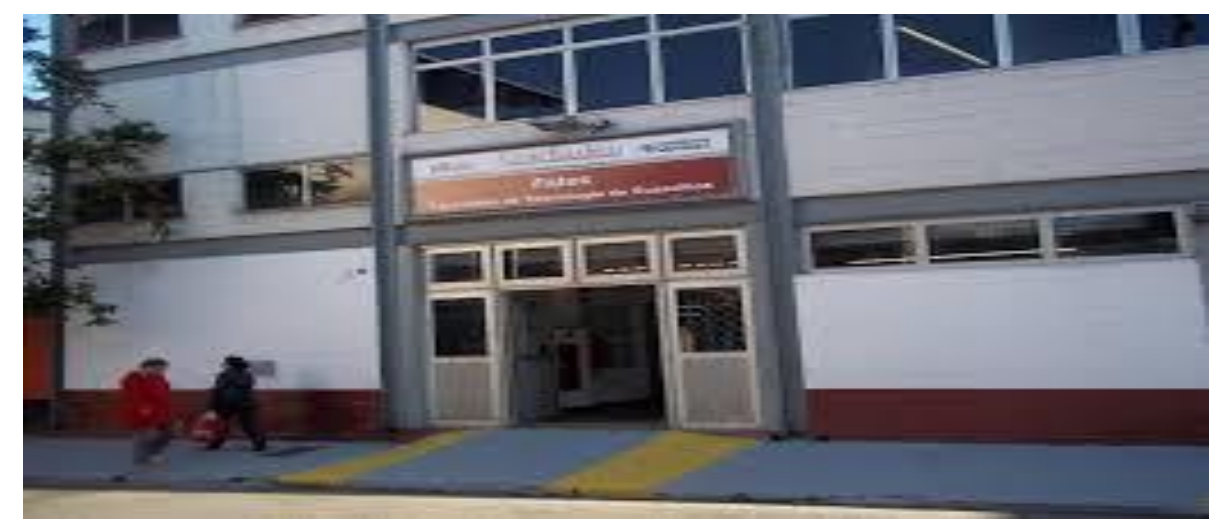

Figura 4: Fachada do Prédio Antigo da Fatec Guarulhos .

Fonte: Fatec Guarulhos (2019) 


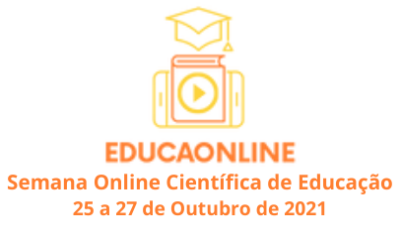

Em janeiro de 2018 ocorreu a mudança para sua sede própria no bairro Parque Cecap (Figura 5). Neste local de $17 \mathrm{mil} \mathrm{m}^{2}$, também, está localizada a Etec de Guarulhos, passou a oferecer além dos Cursos de Logística Aeroportuária (manhã) e Logística (Tarde e noite), os cursos de Comércio Exterior (manhã) e Gestão da Produção Industrial (noite).

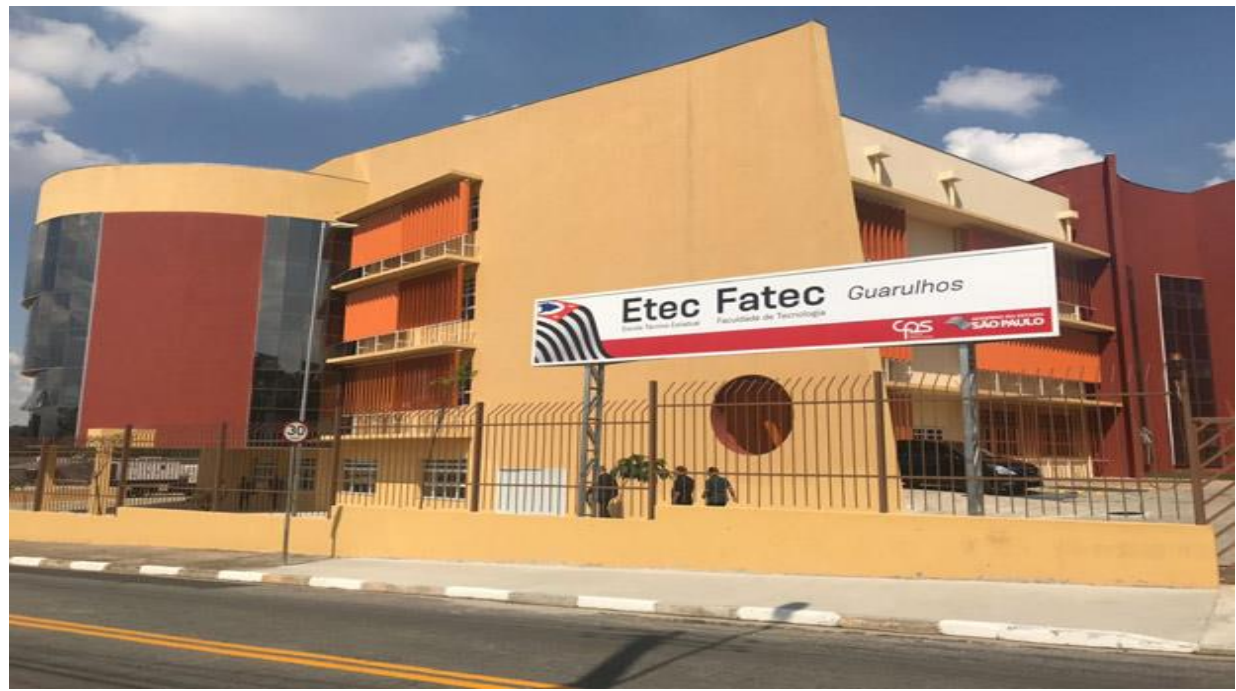

Figura 5: Fachada do Prédio Atual da Fatec Guarulhos.

Fonte: os autores (2019)

Neste prédio que, conta com 24 salas de aula, 17 laboratórios (1 de comandos elétricos, 1 de eletricidade e eletrônica, 1 de ensaios metalográficos, 1 de hidráulica e pneumática, 6 de informática, 1 de maquetes, 1 de metrológica, 1 de processos e fabricação, 1 de robótica aplicada, 1 de simulação de sistemas, 1 de sistema integrado de manufatura, 1 de instalações elétricas), biblioteca, anfiteatro (com 117 lugares), salas de Direção Geral, Diretoria de Serviços Administrativos, Diretoria de Serviços Acadêmicos, Sala de Coordenação, Sala dos Professores; a quantidade de funcionários continuou igual.

No que diz respeito à sua presença na internet, o portal da Fatec Guarulhos disponibiliza informações gerais que incluem suas ações acadêmicas e temas específicos para toda a comunidade como cursos externos e eventos. As redes sociais como Instagram (@fatec_guarulhos) e Facebook (Faculdade de Tecnologia de Guarulhos) integram o conjunto de instrumentos de relacionamento da Instituição com sua Comunidade.

$\mathrm{Na}$ área de educação em particular, a Unidade foi uma das pioneiras quanto ao uso do Sistema Integrado de Gestão Acadêmica (Siga) no ano de 2015. Esta plataforma tem como objetivo facilitar e simplificar o acesso dos alunos as suas informações acadêmicas, 


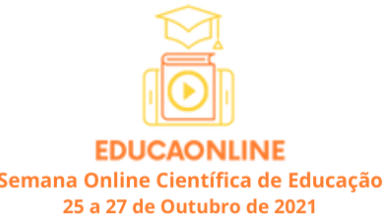

disponíveis principalmente nos sistemas acadêmicos Siga e Diário de Classe. O aplicativo possui as funcionalidades mais acessadas nos sistemas acadêmicos como: consulta às matrículas, ocorrências, planos de estudos, diário (notas e frequência), documentos autenticáveis e relatórios. Nele é possível gerar o comprovante de matrícula e visualizar a carteira de identificação. As notificações são enviadas a cada alteração nas matrículas bem como inserção e alteração de notas e faltas, assim como o lançamento de ocorrências acadêmicas e curriculares. Para este acesso são necessários login e senha informados no ato da matrícula.

Deste modo, a proposta conceitual para implantação da Smart campus Ftc Gru, a nosso ver, vem a corroborar com informações gerais sobre a Unidade como: cardápio do restaurante (quando houver), calendário acadêmico, comunicados em geral, data de provas, atividades, horários e trajetos do transporte coletivo, alunos (saldo do cartão de transporte, por exemplo, notas), consulta de ramais, pontos de interesse, pontos comerciais, escolta/vigilância, biblioteca (consulta, reserva e renovação de materiais), achados \& perdidos, consulta e agendamento de laboratórios e/ou equipamentos, indicadores de eventos científicos e da produção intelectual de alunos, professores e funcionários, serviços de informações ao cidadão, notícias (jornais), agenda de eventos, calendário de apresentação de trabalhos de Conclusão de Cursos, Guia cultural - ações úteis, por exemplo, de acessibilidade e mobilidade que muito contribuem para a qualidade de vida de nossa comunidade acadêmica ao campus - na palma de sua mão (Figura 6).
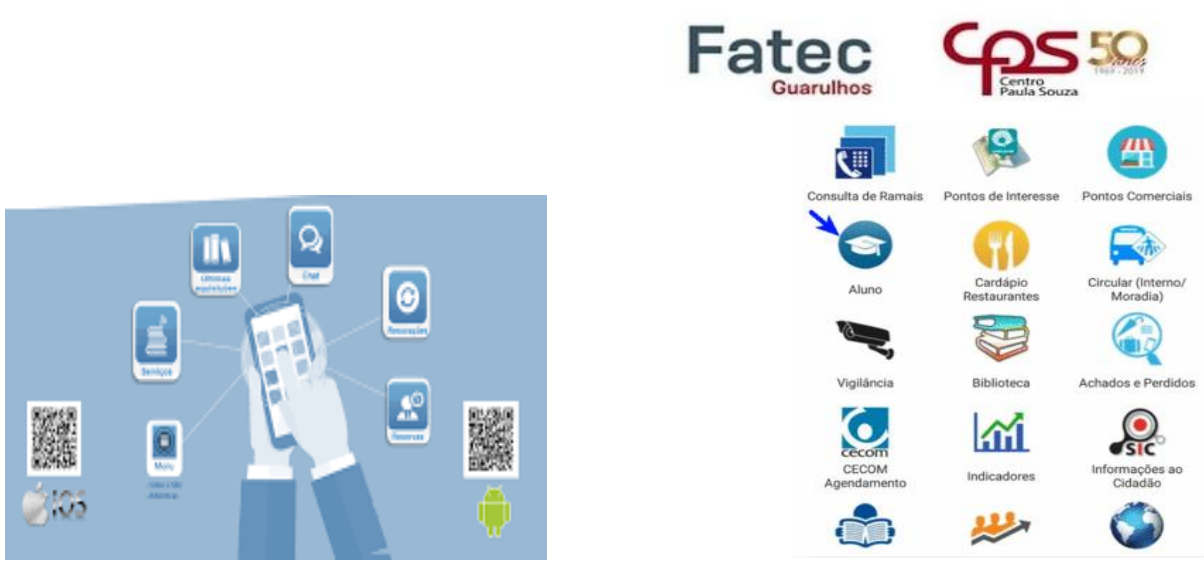

Figura 6: Aplicativo Fatec Gru.

Fonte: os autores (2019) 
Nosso objetivo é ampliar os canais de comunicação utilizando tecnologias móveis. Com isso, espera-se facilitar ainda mais o acesso aos serviços da Fatec Guarulhos pelos seus usuários em um local integrado.

Outra proposta, seria os alunos acessarem o aplicativo - Fatec Pocket $\bigcirc$ (Figura 7 e 8), por exemplo. A ideia é que o usuário faça download do aplicativo na plataforma Android, usando o dispositivo móvel. Lá, acessar o aplicativo no "play store” e procurar por Fatec Pocket. Já na plataforma IOS, usando o dispositivo móvel, acessar o aplicativo "app store" e procurar por Fatec Pocket.
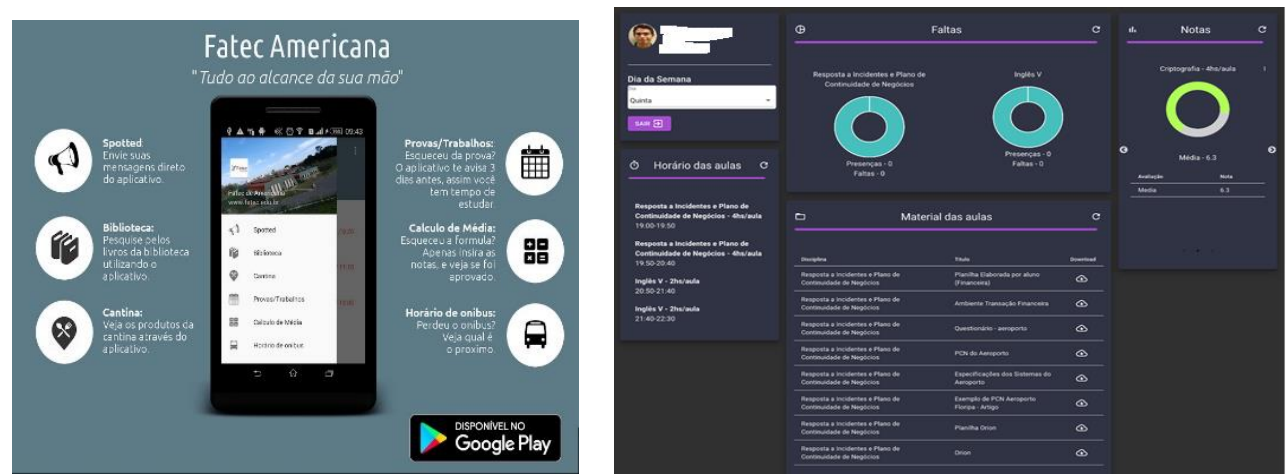

Figura 8: Aplicativo Fatec Pocket.

Fonte: Fatec Pocket (2019)

\section{CONSIDERAÇÕES FINAIS}

Em virtude dos fatos mencionados, podemos verificar que o conceito de Smart campus viabiliza o desenvolvimento do ecossistema urbano tecnológico. Através das pesquisas verificamos que a aplicabilidade desse sistema em ambiente acadêmico, traz benfeitorias a todos os envolvidos - professores, alunos, funcionários - pois garante que todas as informações pertinentes estejam disponíveis e de fácil acesso. Por todos esses aspectos a utilização desse conceito mostra a eficiência em gerir a instituição e garantir que tanto alunos, quanto professores tenha uma experiência proveitosa dentro da instituição.

Conclui-se que esse estudo contribui com a agenda de pesquisa e discussão sobre gestão do espaço acadêmico e mostra-se capaz de ampliar, medir e planejar projetos simples juntamente com o grupo acadêmico; além de provar que as instituições estão 
sendo usadas como laboratórios para a criação de sistemas e conceitos tecnológicos Smart campus - irá proporcionar o uso adequado da tecnologia.

\section{REFERÊNCIAS}

BREDA, G.D; MENDES, L. de S.; PANHAN, A.M.CONSTRUINDO CIDADES INTELIGENTES. Curitiba: Ed. Appris, 2016.

CIDADE UNIVERSITÁRIA PEDRA BRANCA. Disponível em: https://www.cidadepedrabranca.com.br. Acesso em 03 de março de 2019.

CHIUSOLI, C.L. CIDADES E INFORMAÇÕES INTELIGENTES PARA OS CIDADÃOS. Curitiba: Ed. Appris, 2019.

COMO CRIAR SEU PROJETO DE SMART CAMPUS. Disponível em: http://www.konkerlabs.com/. Acesso em 14 junho 2019.

DECRETO DE FUNDAÇÃO DA FATEC GUARULHOS. Disponível em: http://www.portal.cps.sp.gov.br/quem-somos/departamentos/cgd/nucleo-dedocumentacao/para-as-unidades-de-ensino/legislacao-de-criacao-fatecs/metropolitanasao-paulo/fatec-guarulhos-criacao.pdf. Acesso em 10 de Jul. de 2019.

FACHADA DO ANTIGO PRÉdIO DA FATEC GUARULHOS. Disponível em: www.fatecguarulhos.edu.br. Acesso em 12 de set. 2019.

GALlO, D. S. MONITORAMENTO COLABORATIVO PARA CIDADES INTELIGENTES. Disponível em: http://www.teses.usp.br/teses/disponiveis/3/3141/tde-22092016105327/publico/DiegoSanchezGalloCorr16.pdf .Acesso em 10 de Jul. 2019.

HISTÓRICO. FATEC GUARULHOS. Disponível em: http://www.centropaulasouza.spg.gob.br/quemsomos/perfil-historico. Acesso em 10 Set. 2019.

MARCONI, M. A.; LAKATOS, E.M. METODOLOGIA DO TRABALHO CIENTÍFICO: PROCEDIMENTOS BÁSICOS, PESQUISA BIBLIOGRÁFICA, PROJETO E RELATÓRIO, PUBLICAÇÕES E TRABALHOS CIENTÍFICOS. São Paulo: Atlas, 2009.

SOARES NETO, V. CIDADES INTELIGENTES: GUIA PARA CONSTRUÇÃO DE CENTROS URBANOS EFICIENTES E SUSTENTÁVEIS. Curitiba: Ed. Érica, 2018 . 
YIN, R. K. ESTUdO DE CASO: PLANEJAMENTO E MÉTODOS. 2. ed. Porto Alegre: Bookman, 2001. 